\title{
Acetone Extract of Cornus officinalis Leaves Exerts Anti-Melanoma Effects via Inhibiting STAT3 Signaling
}

\author{
Ruiqi $X u^{1,2}$ \\ Mengnan Zeng ${ }^{1,2}$ \\ Yuanyuan Wu ${ }^{1,2}$ \\ Shengchao Wang $\mathbb{D}^{1,2}$ \\ Beibei Zhang ${ }^{1,2}$ \\ Jingke Zhang ${ }^{1,2}$ \\ Yuxuan Kan ${ }^{1,2}$ \\ Benke $\mathrm{Li}^{1,2}$ \\ Bing Cao ${ }^{1,2}$ \\ Xiaoke Zheng $\mathbb{D}^{1,2}$ \\ Weisheng Feng ${ }^{1,2}$ \\ 'School of Pharmacy, Henan University of \\ Traditional Chinese Medicine, \\ Zhengzhou, People's Republic of China; \\ ${ }^{2}$ The Engineering and Technology Center \\ for Chinese Medicine Development of \\ Henan Province, Zhengzhou, People's \\ Republic of China
}

Correspondence: Xiaoke Zheng;

Weisheng Feng

School of Pharmacy, Henan University of

Traditional Chinese Medicine, 156 Jinshui

East Road, Zhengzhou, 450046, People's

Republic of China

Tel +86-37l-6019-0296

Email zhengxk.2006@I63.com;

fwsh@hactcm.edu.cn
Purpose: This research aims to investigate the intervention and mechanism of $50 \%$ acetone extract of $C$. officinalis leaves (SZYY) on melanoma xenografts.

Patients and Methods: Tumor size and cardiac function were measured via ultrasound. The accumulation of 2-deoxy-D-glucose (2-DG) in tumor tissue was examined with nearinfrared in vivo imaging. Flow cytometry was performed to assess apoptosis and reactive oxygen species (ROS) levels in tumor and immune cells in spleen. The levels of inflammatory cytokines in serum were detected by cytometric bead array. The expression of proliferation-, apoptosis-, and angiogenesis-related proteins in tumor cells was measured to evaluate the underlying mechanisms. Subsequently, the effects of four compounds separated from SZYY on the proliferation and migration of A375 cells and STAT3 signaling were examined. The peak identification and contents of the four components were performed via highperformance liquid chromatography (HPLC). Finally, we evaluated the inhibitory effects of STAT3 overexpression on the cytotoxic activity of four constituents in A375 cells.

Results: SZYY inhibited the growth and glycolysis of melanoma xenograft in mice, improved cardiac function, increased the percentages of macrophages, neutrophils, and lymphocytes in spleen, reduced the levels of IL-6, IL-17A, TNF- $\alpha$, and IFN- $\gamma$ in serum, promoted apoptosis and oxidative stress in tumor tissues, and inhibited STAT3 phosphorylation and expression of angiogenic factors. Chemical analysis showed that SZYY is rich in loganin, rutin, triohimas $\mathrm{C}$, and triohimas $\mathrm{D}$, which all could restrain the proliferation and migration of A375 cells and inhibit the phosphorylation and nuclear translocation of STAT3. Moreover, STAT3 overexpression could diminish the cytotoxic activity of four compounds on A375 cells.

Conclusion: SZYY could exert anti-melanoma effects via inhibiting STAT3 signaling to induce apoptosis and inhibit tumor angiogenesis. Its active ingredients might be loganin, rutin, triohimas $\mathrm{C}$, and triohimas $\mathrm{D}$.

Keywords: Cornus officinalis, melanoma, STAT3, apoptosis, angiogenesis

\section{Introduction}

Melanoma is known as a common malignant tumor with high recurrence and metastasis rates and poor prognosis, whose incidence is increasing rapidly in all regions of the world. According to reports, each year more than 65,000 people in the US are given a new diagnosis of invasive melanoma of the skin. Although research about melanoma have increased ceaselessly over the past few decades ${ }^{1}$ and a variety of therapies have been developed and applied to clinical patients, the mortality rate of melanoma is still higher than $13 \% .^{2}$ Furthermore, most traditional chemotherapy could cause varying degrees of injury to the body due to the low 
response rate and the high toxicities. ${ }^{3}$ Therefore, safe and effective targeted chemotherapeutic agents need to be further explored for the treatment of melanoma.

Signal transducer and activator of transcription 3 (STAT3), a DNA-binding transcription factor, is constitutively activated in a variety of human cancers, including melanoma, colorectal cancer, and breast cancer, ${ }^{4-6}$ which could promote proliferation, survival, and invasion of tumor cells, inhibit the anti-tumor immunity, and mediate tumor-promoting inflammation to some extent. ${ }^{7}$ Emerging evidence has shown that it is a major oncogene in melanoma and validated as a target for melanoma therapy. ${ }^{8}$

It is generally found that the non-traditional medicinal parts of Chinese medicine have the same or similar chemical constituents and functions as the traditional medicinal parts, and even new chemical constituents are separated from them. ${ }^{9}$ For example, Yang Fang et al isolated compounds 1, 5-7, and 10 from the Eucommia genus for the first time. ${ }^{10}$ Moreover, Eucommia ulmoides leaves were used instead of E. ulmoides to treat hypertension ${ }^{11}$ and hyperlipidemia ${ }^{12}$ in clinical practice, and the results were satisfactory. The dried pulp of ripe Cornus officinalis Sieb. et Zucc has the effects of tonifying liver and kidney and astringing. Modern pharmacological studies have shown that gallic acid, oleanolic acid, and ursolic acid contained in C. officinalis fruits have excellent anti-tumor activity. ${ }^{13-15}$ Moreover, some promising candidates for the prevention or treatment of metastatic melanoma, such as quercetin, (-)-epicatechin-3-O-gallate, flavanols, etc. are also present in C. officinalis. ${ }^{16-18}$ However, there is a scarcity of research on the chemical constituents and pharmacological activities of $C$. officinalis leaves. This indirectly leads to the waste of $C$. officinalis medicinal resources. In this study, we evaluated the anti-melanoma effects of SZYY in vivo and explored the role of STAT3 signaling, and thereby open up a new way for the development and utilization of $C$. officinalis leaves.

\section{Materials and Methods}

\section{Chemicals and Reagents}

High glucose Dulbecco's modified Eagle's Medium (DMEM, GIBCO, PA, USA). Fetal bovine serum (FBS, EVERY GREEN, China). Penicillin/streptomycin ( $\mathrm{P} / \mathrm{S}$, GIBCO, USA). AG490 (HY-12000, MCE). 3-(4,5-dimethylthiazol-2-yl)-2,5-diphenyltetrazolium bromide (MTT) and dimethyl sulfoxide (DMSO) (Solarbio, Beijing, China). Docetaxel (114977-28-5, aladdin, shanghai, china). IL-6 (Mouse IL-6 Flex Set, 558301, BD), IL-17A (Mouse IL-17A Flex Set, 560283, BD), TNF- $\alpha$ (Mouse TNF Flex Set, 558299, BD), IFN- $\gamma$ (Mouse IFN- $\gamma$ Flex Set, 558296, BD). DAPI staining reagent (G1012, servicebio, Wuhan, China). SZYY obtained from $C$. officinalis Planting Base in Taiping Town, Xixia County, Nanyang City, Henan Province, China.

\section{Cell Culture}

Human melanoma A375 cells, purchased from Procell Life Science \& Technology Co., Ltd., were cultured in DMEM supplemented with $10 \% \mathrm{FBS}$ and $1 \%$ penicillin/streptomycin and maintained at $37^{\circ} \mathrm{C}$ and $5 \% \mathrm{CO}_{2}$. A375 cells successfully transfected with either Stat3C-expressing construct or the empty vector were generously donated by professor Yu from Hong Kong Baptist University. The STAT3-C Flag pRc/CMV construct was obtained from Addgene (USA). A375 cells were transfected with empty vector and the STAT3C-expressing construct for $48 \mathrm{~h}$ and cultured in DMEM supplemented with 10\% FBS, 1\% penicillin/streptomycin and G418 $(300 \mu \mathrm{g} / \mathrm{mL}, 345810$, EMD Millipore Corp).

\section{Nude Mouse Xenograft Model}

Male nu/nu BALB/c mice (5 weeks old), obtained from BEIJING HFK BIOSCIENCE CO., LTD., (License number: SCXK (Beijing) 2019-0008), were allowed to adapt to the new environment for 1 week. All procedures complied with the Guidelines for Care and Use of Laboratory Animals of Henan University of Chinese Medicine, and the experiments were approved by the Animal Ethics Committee of Henan University of Chinese Medicine (Ethics number: DWLL2018080003). A375 cells were resuspended in phosphate-buffered saline (PBS) to a final concentration of $1 \times 10^{7}$ cells per milliliter. Except the normal control group $(\mathrm{n}=10$, Con), each nude mouse was subcutaneously inoculated with $0.2 \mathrm{~mL}$ of A375 cell suspension into the back and kept for 7 days. After that, tumor-bearing mice were randomly divided into the model group $(n=10, M)$, the positive control group (treated with $20 \mathrm{mg} / \mathrm{kg}$ docetaxel) $(\mathrm{n}=10, \mathrm{Y})$, the low dose group (treated with $200 \mathrm{mg} / \mathrm{kg} 50 \%$ acetone extract of C. officinalis leaves [SZYY]) ( $\mathrm{n}=10, \mathrm{SZYY}-\mathrm{Low})$, and the high dose group (treated with $400 \mathrm{mg} / \mathrm{kg}$ SZYY) $(\mathrm{n}=$ 10, SZYY-High), and then intragastrically administered once every other day for 21 days. The Con and $\mathrm{M}$ groups were given the same amount of sterile water. 
Tumor size was measured via ultrasound every 7 days. On the 22nd day, the accumulation of 2-DG probe in tumor tissue was examined with near-infrared in vivo imaging. Cardiac function was detected by Doppler echocardiography. Blood was collected for subsequent detection of related cytokines in serum. The tumor and spleen were subjected to further analysis.

\section{Flow Cytometric Analysis of Immune Cells}

The fresh spleen tissue was ground on a $70 \mu \mathrm{m}$ filter, and then washed with PBS to pass the cells through the $70 \mu \mathrm{m}$ filter. About $5 \times 10^{5}$ primary cells from mice spleens were collected for each detection. The cells were resuspended in $300 \mu \mathrm{L}$ of PBS and then incubated with anti-Ly-6G, antiF4/80, anti-CD4, and anti-CD8 in the dark for $30 \mathrm{~min}$ at $25^{\circ} \mathrm{C}$. After washing twice with PBS, the cells were subjected to flow cytometry analysis (FACS Aria ${ }^{\mathrm{TM}}$ III, BD) as soon as possible.

\section{Cytometric Bead Array (CBA)}

According to the manufacturer's instructions, a $50 \mu \mathrm{L}$ aliquot of serum from each sample was incubated with $50 \mu \mathrm{L}$ microspheres at room temperature for $2 \mathrm{~h}$ in the dark. Subsequently, $50 \mu \mathrm{L}$ PE-conjugated IL-6, IL-17A, TNF- $\alpha$, or IFN- $\gamma$ antibody was added and samples were incubated at room temperature for $1 \mathrm{~h}$ in the dark. Following washing with CBA wash buffer, the samples were re-suspended in $500 \mu \mathrm{L}$ buffer. The content of cytokines was measured by flow cytometry, and the results were analyzed by flow cytometry. Standard curves were plotted based on the increasing concentrations of the reference standards.

\section{Determination of Apoptosis and ROS in the Tumor Tissues}

The fresh tumor tissue was cut into $1 \mathrm{~mm}$ pieces, washed twice with $\mathrm{PBS}$ and centrifuged for $2 \mathrm{~min}$ each $\left(4^{\circ} \mathrm{C}\right.$, $1500 \mathrm{rpm}$ ), and then the supernatant was discarded. The shredded tissue was digested using trypsin $(0.25 \%)$ at room temperature for $3 \mathrm{~min}$, and digestion was terminated by adding a small amount of serum. Subsequently, the cells were collected by using PBS to rinse the tissue and filtering through a $70 \mu \mathrm{m}$ filter. According to the manufacturer's instructions, the evaluation of apoptotic effects in tumor cells was conducted by Annexin V-PE/7-AAD double staining using the PE Annexin V Apoptosis
Detection Kit I (559763, BD), and the detection of ROS levels in the tumor tissues was performed using DCFHDA fluorescent probes (CA1410, Solarbio). Flow cytometry was applied to samples, followed by data analysis.

\section{Near-Infrared in vivo Imaging}

Aerobic glycolysis, characterized by high glucose uptake, of cancer cells generally is abnormally elevated to meet the requirements for survival and rapid growth. ${ }^{19}$ Therefore, 2-DG, an analog of glucose, can be used to reflect the level of aerobic glycolysis in the tumor. Maximum absorption wavelength and maximum emission wavelength are 774 and $789 \mathrm{~nm}$, respectively. Mice were injected with the IRDye ${ }^{\circledR}$ 800CW 2-DG optical probe (C71103-07, LI-COR Biosciences, USA) through the tail vein, ${ }^{20}$ and scanned with a near-infra red fluorescence imaging system (Pearl, Li-COR Biosciences, USA) $14 \mathrm{~h}$ later. The fluorescence signal in the specified area was normalized analysis using Pearl Image Studio v3.1 software (Li-COR Biosciences, USA).

\section{Western Blot Analysis}

The total protein of tumor tissue was collected with RIPA protein lysate, and the protein concentration was detected using a BCA protein quantification kit (PC0020, Solarbio). For Western blotting, proteins (60 $\mu \mathrm{g} / \mathrm{sample})$ from tumor tissue lysates were subjected to $10 \%$ SDSPAGE and then transferred to PVDF membranes using a semi-dry system (Bio-Rad). Subsequently, the membranes were blocked with 5\% BSA for $90 \mathrm{~min}$ at room temperature and then incubated with primary antibodies at $4^{\circ} \mathrm{C}$ overnight, including antibodies against STAT3 (1: 1000, \#9139S, CST), p-STAT3 (1: 2000, \#9145S, CST), Ki-67 (1: 100, MA5-14520, ThermoFisher), Mcl-1 (1: 1000, MA5-32060, ThermoFisher), Bcl-xL (1: 1000, MA5-15142, ThermoFisher), Bcl-2 (1: 50, MA5-11757, ThermoFisher), cleaved caspase-3 (1:500, ab49822, Abcam), and beta Actin (1:1000, ab8226, Abcam). Finally, the goat anti-rabbit IgG (925-6807, LI-COR) or goat anti-mouse IgG (925-32210, LI-COR) secondary antibody was added and incubated with membranes for 1 $\mathrm{h}$ at room temperature. The protein bands were scanned using two-color infrared laser imaging system (ODYSSEY CLX, USA) and analyzed using the Image Studio software.

\section{Cell Viability Assay}

A375 cells were seeded into 96-well plates (3599, Corning, USA) at 4000 cells/well and treated with either vehicle 
control (DMSO) or a compound separated from SZYY for 48 h. Subsequently, $20 \mu \mathrm{L}$ MTT solution $(5 \mathrm{mg} / \mathrm{mL})$ was added to each well and samples were incubated for $4 \mathrm{~h}$ at $37^{\circ} \mathrm{C}$. After removing the medium, $150 \mu \mathrm{L}$ DMSO was added to dissolve the violet crystal. The OD value at a wavelength of $490 \mathrm{~nm}$ was measured with an EPOCH microplate reader (BioTek, VT, USA) after shaking for $10 \mathrm{~min}$. Cell viability was determined by comparing OD values with those of vehicle-treated control cells $(100 \%)$.

\section{Cell Migration Assay}

A375 cells were seeded into 96-well plates at 4000 cells/well and divided into the control, AG490 (10 $\mu \mathrm{M})$, Loganin $(50 \mu \mathrm{M})$, Rutin $(50 \mu \mathrm{M})$, Triohimas $\mathrm{C}(50 \mu \mathrm{M})$, Triohimas D $(50 \mu \mathrm{M}), \mathrm{AG} 490+$ Loganin $(10 \mu \mathrm{M}+50 \mu \mathrm{M}), \mathrm{AG} 490+$ Rutin $(10 \mu \mathrm{M}+50 \mu \mathrm{M}), \mathrm{AG} 490+$ Triohimas $\mathrm{C}(10 \mu \mathrm{M}+50$ $\mu \mathrm{M})$, and $\mathrm{AG} 490+$ Triohimas $\mathrm{D}(10 \mu \mathrm{M}+50 \mu \mathrm{M})$ treatment groups. The migration dynamics of cells were monitored by Digital Phase Contrast of the the High Content Screening System (Opera Phenix, PerkinElmer, Shanghai, China) for $48 \mathrm{~h}$ at $37^{\circ} \mathrm{C}$ and $5 \% \mathrm{CO} 2$.

\section{In-Cell Western}

The cell layers were fixed with $3.7 \%$ paraformaldehyde at room temperature for $20 \mathrm{~min}$ and then permeabilized by washing five times with $0.1 \%$ Triton $\mathrm{X}-100$ for 5 min each time. Subsequently, the cell monolayers were blocked with $5 \%$ BSA for $90 \mathrm{~min}$ and then incubated with antibodies against JAK2 (1:50, PA5-11267, ThermoFisher), p-JAK2 (1:500, PA5-105889, ThermoFisher), Src (1:50, MA511173, ThermoFisher), p-Src (1 $\mu \mathrm{g} / \mathrm{mL}, \quad 44-662 \mathrm{G}$, ThermoFisher), STAT3, or p-STAT3 for overnight at $4^{\circ} \mathrm{C}$. After washing with $0.2 \%$ PBST, the cell layers were stained with goat anti-rabbit IgG or goat anti-mouse IgG, washed, imaged with a two-color infrared laser imaging system, and analyzed using the Image Studio software.

\section{Immunofluorescence Assay}

A375 cells were seeded into 96-well plates at 4000 cells/well and divided into the control, AG490 (10 $\mu \mathrm{M})$, Loganin (50 $\mu \mathrm{M})$, Rutin $(50 \mu \mathrm{M})$, Triohimas $\mathrm{C}(50 \mu \mathrm{M})$, and Triohimas $\mathrm{D}(50 \mu \mathrm{M})$ groups. Following treatment for $48 \mathrm{~h}$, the cells were fixed using 4\% paraformaldehyde for 15 minutes and then permeabilized with $0.25 \%$ Triton X-100 (\#T8200, Solarbio) for 10 minutes. Subsequently, the cell monolayers were blocked with $1 \% \mathrm{BSA}$ for $30 \mathrm{~min}$ at room temperature and then incubated with primary antibodies at $4^{\circ} \mathrm{C}$ overnight, including antibodies against JAK2, p-JAK2, Src, p-Src, and
STAT3. After washing with PBS, Alexa Fluor-conjugated goat anti-rabbit ( $2 \mu \mathrm{g} / \mathrm{mL}, \mathrm{A}-21206$, ThermoFisher) or antimouse (2 $\mu \mathrm{g} / \mathrm{mL}, \mathrm{A}-21235$, ThermoFisher) secondary Antibody was added and incubated with samples for $1 \mathrm{~h}$ at room temperature. Finally, the cell monolayers were counterstained with DAPI ( $2 \mu \mathrm{g} / \mathrm{mL}, \mathrm{G1012}$, Servicebio) for $5 \mathrm{~min}$. Typical images were obtained by scanning with $63 \times$ water mirror on the High Content Screening System.

\section{Chromatographic Conditions}

Fingerprint characterization of SZYY was carried out by using high performance liquid chromatography coupled with photodiode array detection (HPLC-DAD). Loganin, triohimas $\mathrm{C}$, triohimas $\mathrm{D}$, and rutin isolated from SZYY in our laboratory served as reference compounds for quantification. For separation, a Symmetry C18 Column (100A, $5 \mathrm{um}, 4.6 \mathrm{~mm} \times 250 \mathrm{~mm}, 1 / \mathrm{pkg}$ ) was employed with a mobile phase consisting of acetonitrile (eluent A) and $0.1 \%$ formic acid aqueous solution (eluent $\mathrm{B}$ ) at a rate of $1.0 \mathrm{~mL} / \mathrm{min}$. The applied gradient was as follows: $0-15$ $\min , 5 \% \mathrm{~A} ; 15-30 \mathrm{~min}, 5-8 \% \mathrm{~A} ; 30-50 \mathrm{~min}, 8 \%-13 \% \mathrm{~A}$; 50-70 min, 13-23\%; 70-85 min, 23-30\% A; and 85-90 $\min , 30-5 \%$ A. After a $10-$ min equilibration period, samples with a volume of $5 \mu \mathrm{L}$ were injected into the column. The column temperature was kept at $30^{\circ} \mathrm{C}$ and the measurement wavelength was set at $254 \mathrm{~nm}$. The external standard method was used to calculate the content of the four components in SZYY. For the preparation of reference solution, $1 \mathrm{mg}$ of loganin, triohimas $\mathrm{C}$, triohimas $\mathrm{D}$, or rutin was weighed accurately in $10 \mathrm{~mL}$ volumetric flasks, dissolved, and diluted to the mark with methanol, followed by sonication for 30 minutes. For the preparation of test solution, $0.1 \mathrm{~g}$ of SZYY was precisely weighed into a $10-\mathrm{mL}$ volumetric flask, dissolved, and diluted to the mark with $17 \%$ acetonitrile aqueous solution. During this process, it is necessary to shake continuously and sonicate for 30 minutes. After centrifugation, insoluble materials were filtered out with $0.45-\mu \mathrm{m}$ microporous membranes. The extraction rate of SZYY is about $32 \%$.

\section{Statistical Analysis}

Data analysis was performed using SPSS 20.0 (IBM, NY, USA). The results are presented as the mean \pm standard deviation (S.D.). The measurement data of multiple groups were compared with one-way ANOVA followed by LSD's test, or a Student's $t$-test where appropriate. In all analyses, $\mathrm{P}<0.05$ was taken to indicate statistical significance. 


\section{Results}

\section{SZYY Inhibited the Growth of A375}

\section{Melanoma Xenograft in Mice and}

\section{Improved Cardiac Function}

Ultrasound scanning results (Figure 1A) revealed that on the 21st day, the relative tumor volume of the Y, SZYYLow and SZYY-High groups were $20.53 \%, 28.57 \%$ and $24.57 \%$ of that of the model group, respectively. SZYY inhibited the growth of A375 melanoma xenograft in mice (Figure 1B and C). Simultaneously, the reduction in LVEF and LVFS of the model group mice could be efficiently reversed by SZYY $(p<0.01)$ (Figure 1D). LVEF and LVFS are important parameters for evaluating left ventricular function. Western blot results showed the protein levels of Ki-67, a cell proliferation marker, in tumor tissues of
SZYY groups were also significantly decreased compared with the model group $(\mathrm{p}<0.01)$ (Figure 1E). Consistently, the accumulation of 2-DG probes in tumor tissues was decreased observably by SZYY $(\mathrm{p}<0.01)$ (Figure $1 F)$.

\section{SZYY Promoted Apoptosis and the Production of Reactive Oxygen Species (ROS) in the Tumor Tissues}

In comparison with the model group, the apoptosis percentages and ROS production in tumor tissues were significantly increased due to administration of SZYY $(p<0.01)$ (Figure 2A and B). In addition, some apoptosis related proteins were determined by Western blot. As shown in Figure 2C, caspase-3 was obviously upregulated, while Mcl-1, Bcl-xL, and Bcl-2 were significantly

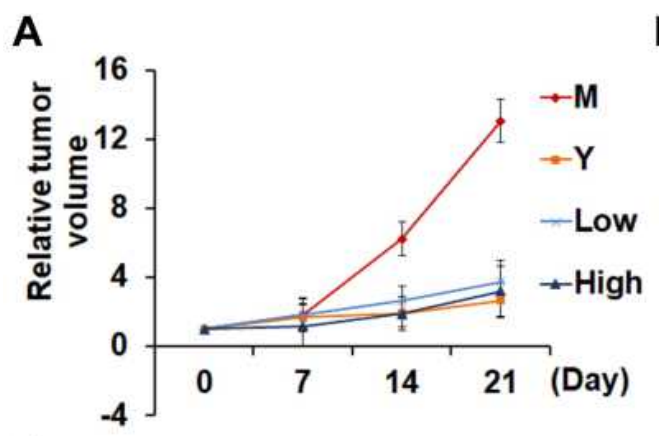

B

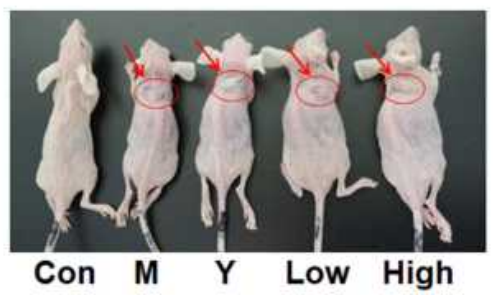

C
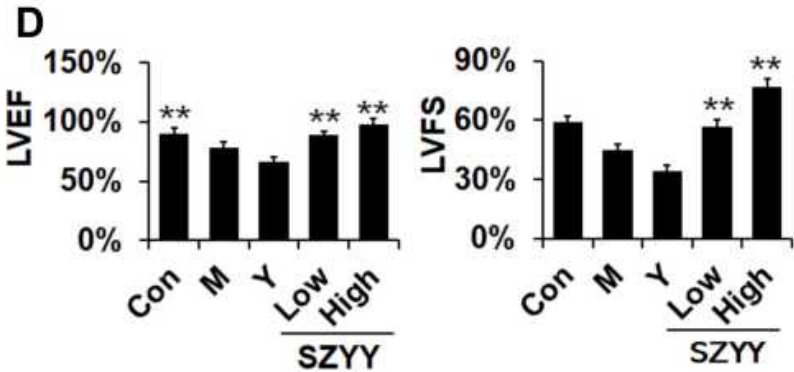

$\mathbf{E}$

$\mathbf{F}$
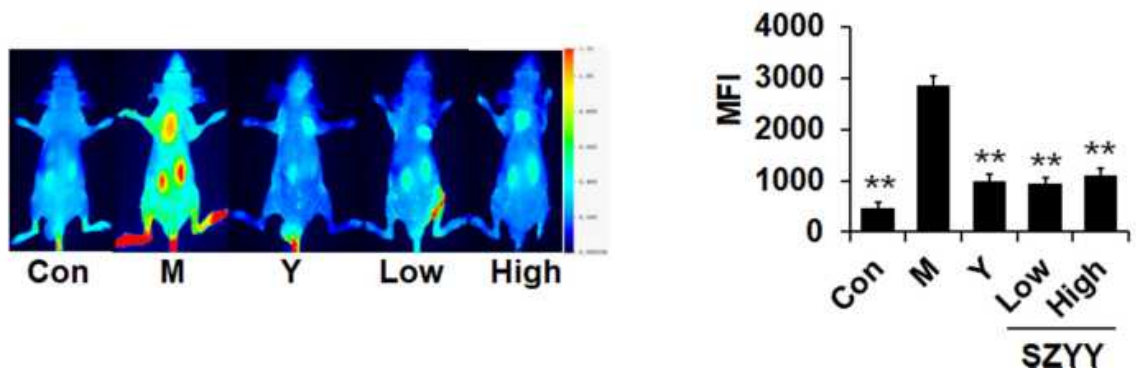

Figure I SZYY inhibited A375 melanoma xenograft growth and improved cardiac function. (A) Relative tumor volume = tumor volume/tumor volume measured the first time. Data obtained by ultrasound. (B and $\mathbf{C}$ ) Photos of tumor-bearing mice and tumors dissected from mice. The subcutaneous neoplasms are shown as the arrows and circles. (D) Effects on cardiac function (LVEF and LVFS) were detected via ultrasound. (E) Effects on Ki-67 in tumor tissue were detected via Western blot. (F) Representative images showed the fluorescent signal of 2-DG probe in mice at $14 \mathrm{~h}$ and quantitative result. $\mathrm{X} \pm \mathrm{SD}$. $\mathrm{n}=3 \mathrm{mice}$ per group. $* * p<0.0 \mathrm{I}$ vs model group. Abbreviations: SZYY, 50\% acetone extract of C.officinalis leaves; LVEF, left ventricular ejection fractions; LVFS, left ventricular fraction shortening; MFI, mean fluorescence intensity. 

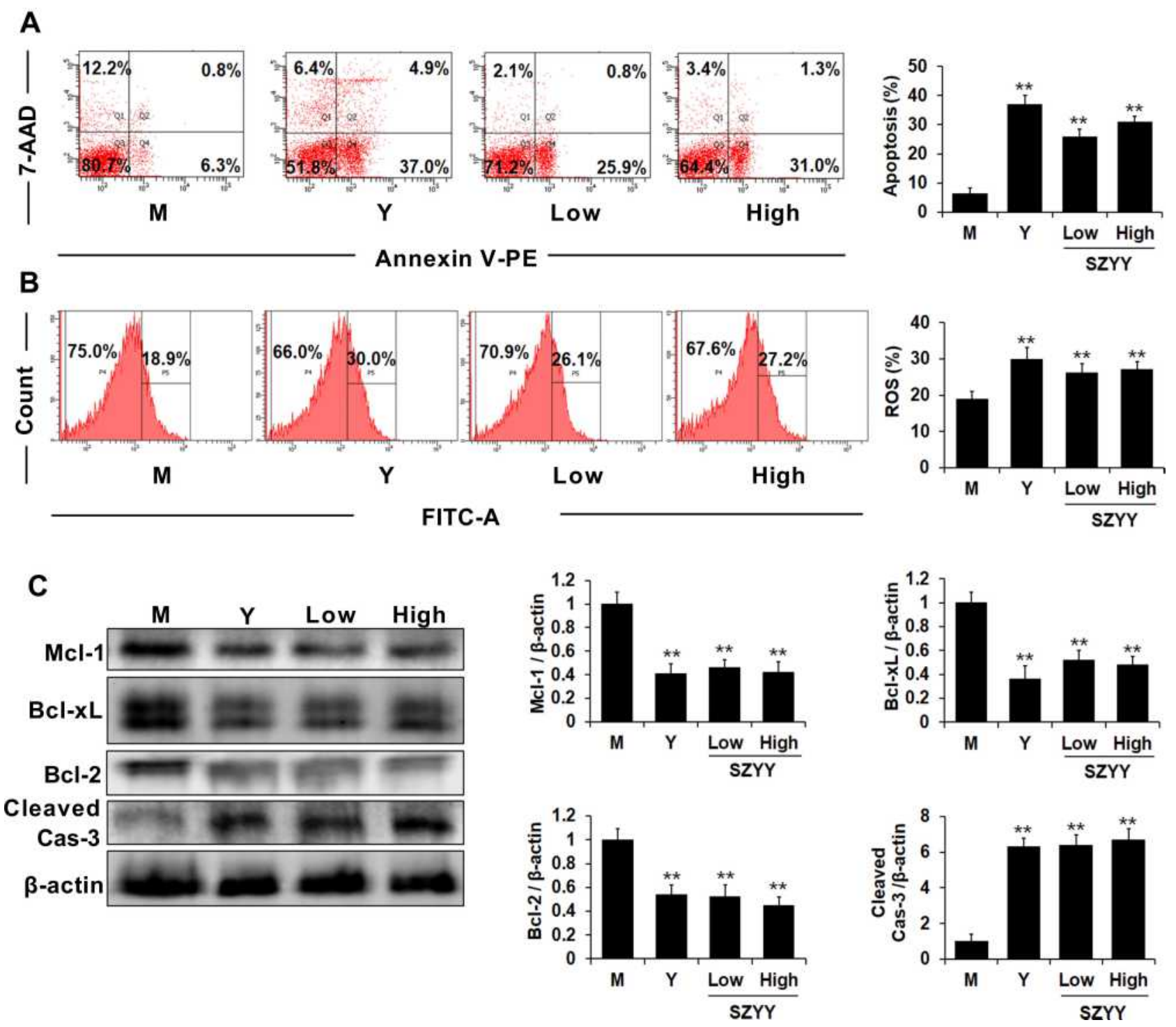

Figure 2 SZYY promoted apoptosis and ROS production in the tumor tissues. (A) The percentage of apoptosis in tumor tissues. (B) The production of ROS in tumor tissues. (C) Effects on Mcl-I, Bcl-xL, Bcl-2 and cleaved caspase-3 in tumor tissues were detected via Western blot. $X \pm S D$. $n=3$ mice per group. ** $p<0.0 \mathrm{I}$ vs model group. Con: the normal control group; $M$ the model group; $Y$ the positive control group (docetaxel, $20 \mathrm{mg} / \mathrm{kg}$ ); Low: the low dose group (SZYY, $200 \mathrm{mg} / \mathrm{kg}$ ); High: the high dose group (SZYY, $400 \mathrm{mg} / \mathrm{kg}$ ).

Abbreviations: SZYY, 50\% acetone extract of C.officinalis leaves; ROS, reactive oxygen species.

downregulated by SZYY $(\mathrm{p}<0.01)$. Moreover, the level of Survivin in tumor tissue was also decreased by SZYY compared with the model group (Figure 4B).

\section{SZYY Improved the Immune Function of Tumor-Bearing Mice and Reduced Inflammation}

As the main immune organ of BALB/c nude mice, the spleen plays a critical role in the initiation of the immune response. To determine the influence of SZYY on the immune function of these tumor-bearing mice, flow cytometry was employed to analyze the levels of immune cells in the spleens. As shown in Figure 3A and C, SZYY-Low exhibited significantly increased the percentages of neutrophils $(\mathrm{Ly}-6 \mathrm{G}+$ ), macrophages $(\mathrm{F} 4 / 80+)$, and Th cells $(\mathrm{CD} 4+)$ in spleens compared to the model group $(\mathrm{p}<0.01)$, but no obvious influence on Tc cells $(\mathrm{CD} 8+)(\mathrm{p}>0.05)$. CBA was performed to detect the levels of cytokines in serum. As shown in Figure 3B and D, the levels of IL-6, IL-17A, TNF- $\alpha$, and IFN- $\gamma$ in serum in the model group were significantly increased compared with the normal group $(p<0.01)$, but which could be significantly decreased by SZYY $(\mathrm{p}<0.01)$. 
A

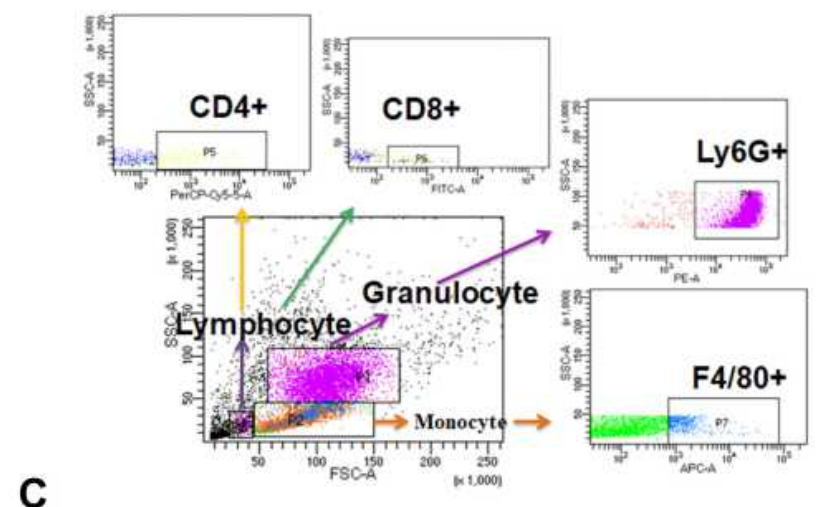

C
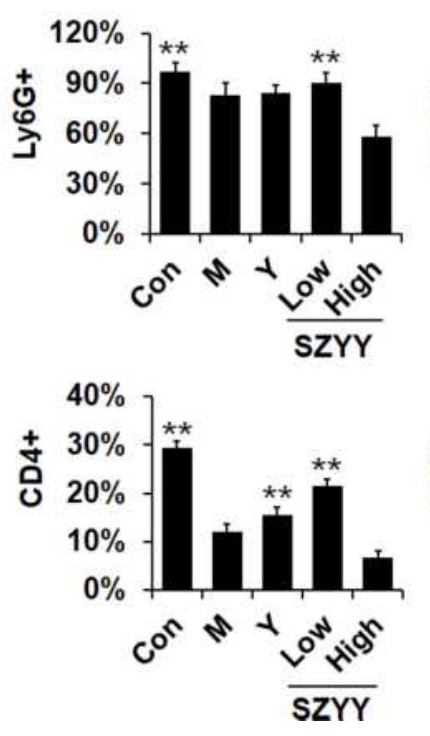

B

D
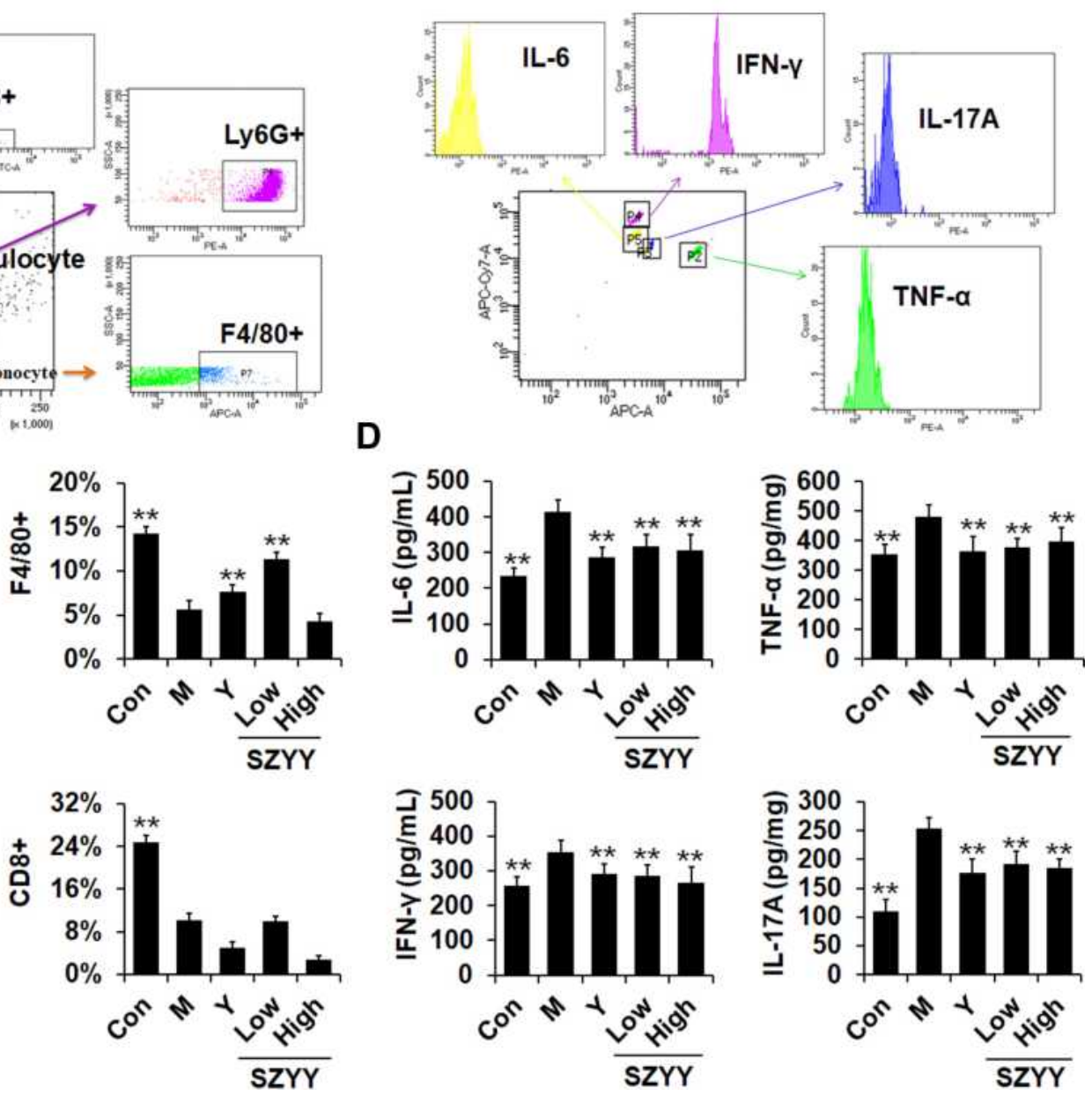
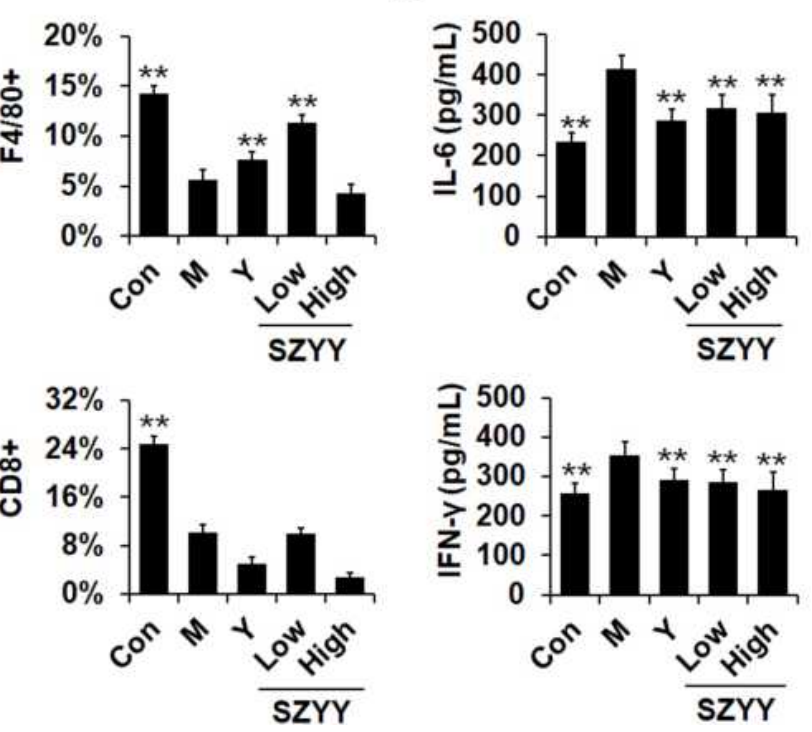

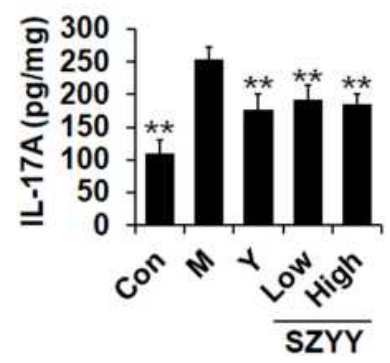

Figure 3 SZYY enhanced immune function of the spleen and improve the immune microenvironment of tumor-bearing mice. (A) Flow cytometry strategy. Relative counts of leukocyte subgroups were quantified by gating on Ly-6G+ for neutrophils, F4/80+ for macrophages and CD4+/CD8+ for lymphocytes. (B) The representative peak graphs of IL-6, TNF- $\alpha$, IFN- $\gamma$ and IL-I7A were obtained by FACS software. (C) Quantitative analysis of neutrophils (Ly-6G+), macrophages (F4/80+) and lymphocytes (CD4+/CD8+) in spleen. (D) Quantitative analysis of IL-6, TNF- $\alpha$, IFN- $\gamma$ and IL-I7A in serum. $X \pm$ SD. $n=3$ mice per group. ** $p<0.01$ vs model group.

Abbreviation: SZYY, 50\% acetone extract of C.officinalis leaves.

\section{SZYY Restrained Phosphorylation/ Activation of STAT3 in Melanoma Xenografts and Inhibited the Expression of Angiogenic Factors}

To further investigate the underlying mechanisms of the anti-melanoma effect of SZYY, the expression of STAT3 and p-STAT3 in tumor tissues were examined. Compared with the model group, administration of Y and SZYY significantly inhibited the phosphorylation of STAT3 at the tyrosine 705 (Tyr705) site $(\mathrm{p}<0.01)$, while there was no effect on total STAT3 expression $(\mathrm{p}>0.05)$ (Figure 4A and $\mathrm{C}$ ). In addition, as shown in Figure $4 \mathrm{~B}$ and $\mathrm{D}$, the expression levels of CD31, VEGF-A and BFGF were decreased in tumor tissues by SZYY compared with the model group, suggesting that SZYY could restrain tumor angiogenesis. Survivin (green) and CD31 (red) positive fluorescent staining overlapped (yellow) in tumor tissues (Figure 4B).

\section{SZYY Reduced the Viability of A375 Cells and Inhibited Their Migration Ability}

To study the pharmacological basis of the anti-melanoma effects of SZYY, the effects of 13 compounds from SZYY on A375 cells were investigated. Results showed that loganin, triohimas $\mathrm{C}$, triohimas $\mathrm{D}$, and rutin could inhibit the proliferation of A375 cells $(p<0.01)$ (Figure 5A). Next, the effects of these four compounds on the migration ability of A375 cells were detected, and the AG490 treatment group was used as a positive control to compare the inhibition of STAT3 by the four compounds. AG490 is a tyrosine kinase inhibitor that can 


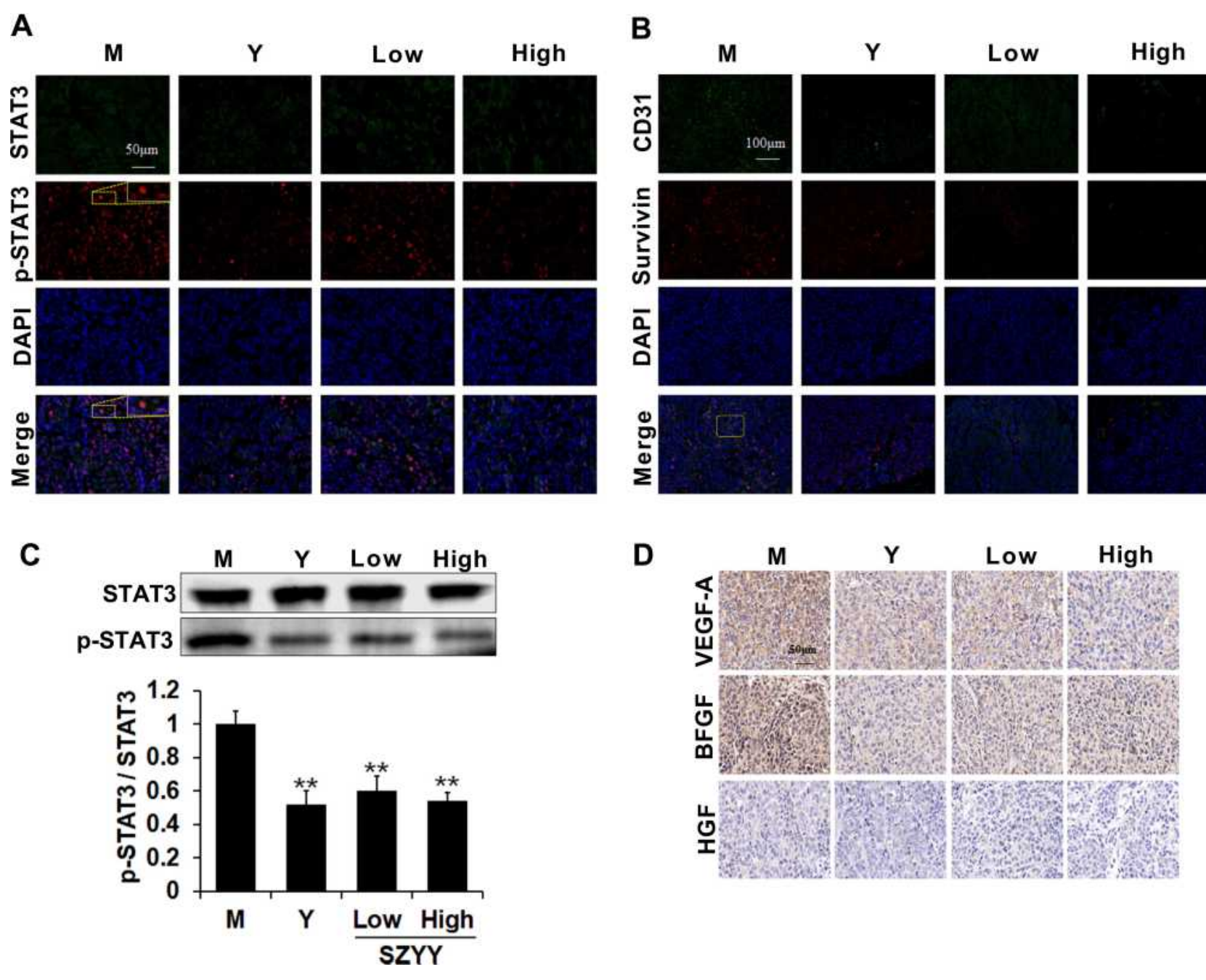

Figure 4 SZYY restrained phosphorylation/activation of STAT3 and the expression of angiogenic factors in melanoma xenografts. (A) Expression of STAT3 (green), p-STAT3 (red) in melanoma slices was evaluated by immunofluorescent double staining. Scale bar $=50 \mu \mathrm{m}$. (B) Expression of CD3I (green), Survivin (red) in melanoma slices was evaluated by Immunofluorescent double staining. Nuclei, blue. Scale bar $=100 \mu \mathrm{m}$. (C) The activation of STAT3 was measured by Western blot. (D) Expression of VEGF-A, BFGF and HGF in melanoma xenografts was detected by Immunohistochemistry $(\times 40)$. Scale bar $=50 \mu m$. $X \pm S D ; n=3$ mice per group; $* * p<0.01$ vs model group. Abbreviation: SZYY, 50\% acetone extract of C.officinalis leaves.

selectively inhibit JAK/Stat-3 activation. As shown in Figure $5 \mathrm{~B}$ and $\mathrm{C}$, loganin could significantly inhibit the migration of A375 cells $(\mathrm{p}<0.01)$, and so do triohimas $C$, triohimas $\mathrm{D}$, and rutin to varying degrees $(p<0.05)$. The above results were consistent with the results obtained by AG490 alone and AG490 combined with compounds ( $p<0.05, p<0.01)$. HPLC analysis showed the contents of loganin, triohimas $\mathrm{C}$, triohimas D, and rutin in SZYY were $0.75 \%, 0.22 \%, 0.48 \%$, and $0.19 \%$ respectively (Figure $6 \mathrm{~A}-\mathrm{F}$ ).

\section{SZYY Reduced Constitutive STAT3 Phosphorylation and Inhibits STAT3 \\ Nuclear Translocation}

The effects of four compounds on the phosphorylation/ activation of STAT3 in A375 cells were tested by cellular immunofluorescence and in-cell Western. The levels of p-STAT3 in A375 cells were reduced significantly upon treatment with the four compounds compared with the control group $(p<0.01)$. In A375 cells co-treated with AG490 and compound, the expression of p-STAT3 was suppressed more obviously compared with the AG490 group $(\mathrm{p}<0.01)$ (Figure 7A). Furthermore, STAT3 expression in the nuclear part of A375 cells was decreased notably by the four compounds $(\mathrm{p}<0.01)$, which suggested that the four compounds could inhibit STAT3 nuclear translocation. Among them, triohimas D has the best nuclear translocation inhibition efficiency, which was equivalent to that of AG490 (Figure 7B). In addition, we also examined the levels of JAK2 and Src in A375 cells, both of which are upstream proteins of STAT3. According 


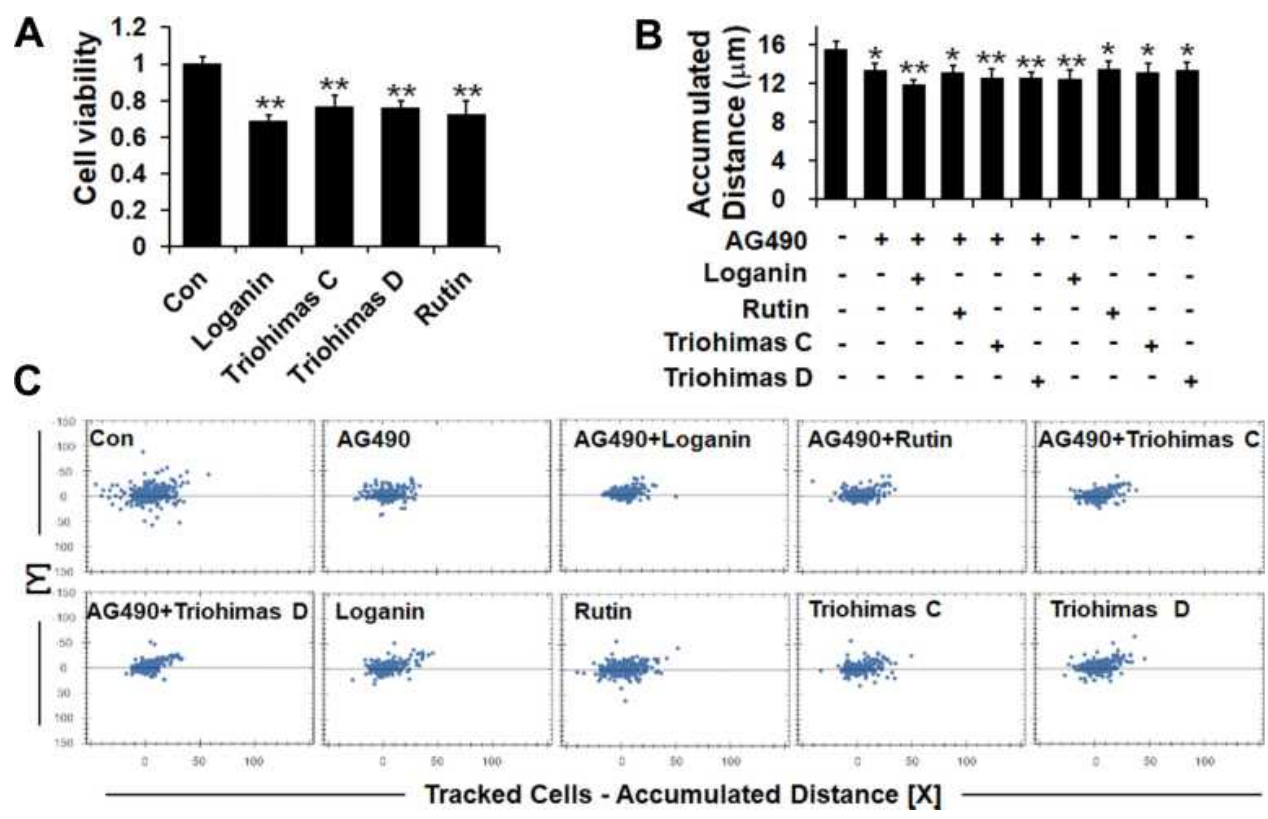

Figure 5 Four compounds reduced the viability of A375 cells and inhibited their migration ability. (A) Effects of four compounds on A375 cells proliferation. (B and C) A375 cells migration ability detected via High Content Screening System. $X \pm$ SD. $n=6$ per group. $* p<0.05$, ** $p<0.01$ vs control group.

to our results (Figure 7C), JAK2 and Src were less affected by these compounds ( $p>0.05$ ), except that $\mathrm{p}-\mathrm{JAK} 2$ levels were observably reduced in the AG490 and AG490+ groups $(\mathrm{p}<0.01)$.

\section{Overexpression of STAT3C Diminished the Inhibitory Effect of SZYY on A375 Cells}

In order to further clarify the role of STAT3 in the occurrence and development of melanoma, we detected the effects of four compounds on the viability of A375 cells transiently transfected with either the empty vector or the STAT3C-expressing construct by the MTT assay. The total STAT3 and p-STAT3 levels were significantly increased in A375 cells transfected with STAT3C-expressing construct $(p<0.01)$ (Figure 8A). As shown in Figure 8B, the viability of A375 cells transfected with STAT3C-expressing construct was less affected by four compounds compared with the cells transfected with the empty vector $(p<0.01)$. STAT3C is an oncogenic mutant form of STAT3 that is constitutively active and continuously highly expressed in cells. The above results suggest that overexpression of STAT3 could effectively diminish the inhibitory effects of the four SZYY compounds on A375 cells.

\section{Discussion}

The incidence of malignant melanoma continues to rise worldwide, but the success rate of current treatment strategies for metastatic melanoma is relatively low, and most emerging anti-melanoma therapies have serious adverse reactions, which all highlight the necessity of developing safe and effective new targeted drugs for melanoma. ${ }^{21,22}$ Natural products and their derivatives have shown great potential in the prevention and treatment of human cancer, ${ }^{23,24}$ such as Vitexin, ${ }^{25}$ Morin, ${ }^{26}$ and Weimaining Capsules, a second-class anti-tumor drug successfully developed with tannin compounds as effective ingredients. ${ }^{27}$ This indicates that certain compounds derived from nature tend to have certain biological activities and are promising as new drugs for the treatment of diseases. Although $C$. officinalis has been reported to have various biological and pharmacological activities, ${ }^{17}$ there is a scarcity of research on the chemical constituents and pharmacological activities of $C$. officinalis leaves. Our study provides some new information about $C$. officinalis leaves used in the treatment of melanoma. Here, we will further discuss the internal mechanisms of SZYY against melanoma in terms of apoptosis, oxidative stress, angiogenesis, immune regulation, and STAT3 signaling.

Apoptosis, as a kind of programmed cell death, is thought to be a non-inflammatory form of cell death and usually manifests as immunological silence. ${ }^{28}$ In cancer, de-regulated apoptotic signaling, particularly the activation of an anti-apoptotic systems, allows cancer cells to escape this program, leading to uncontrolled proliferation, 

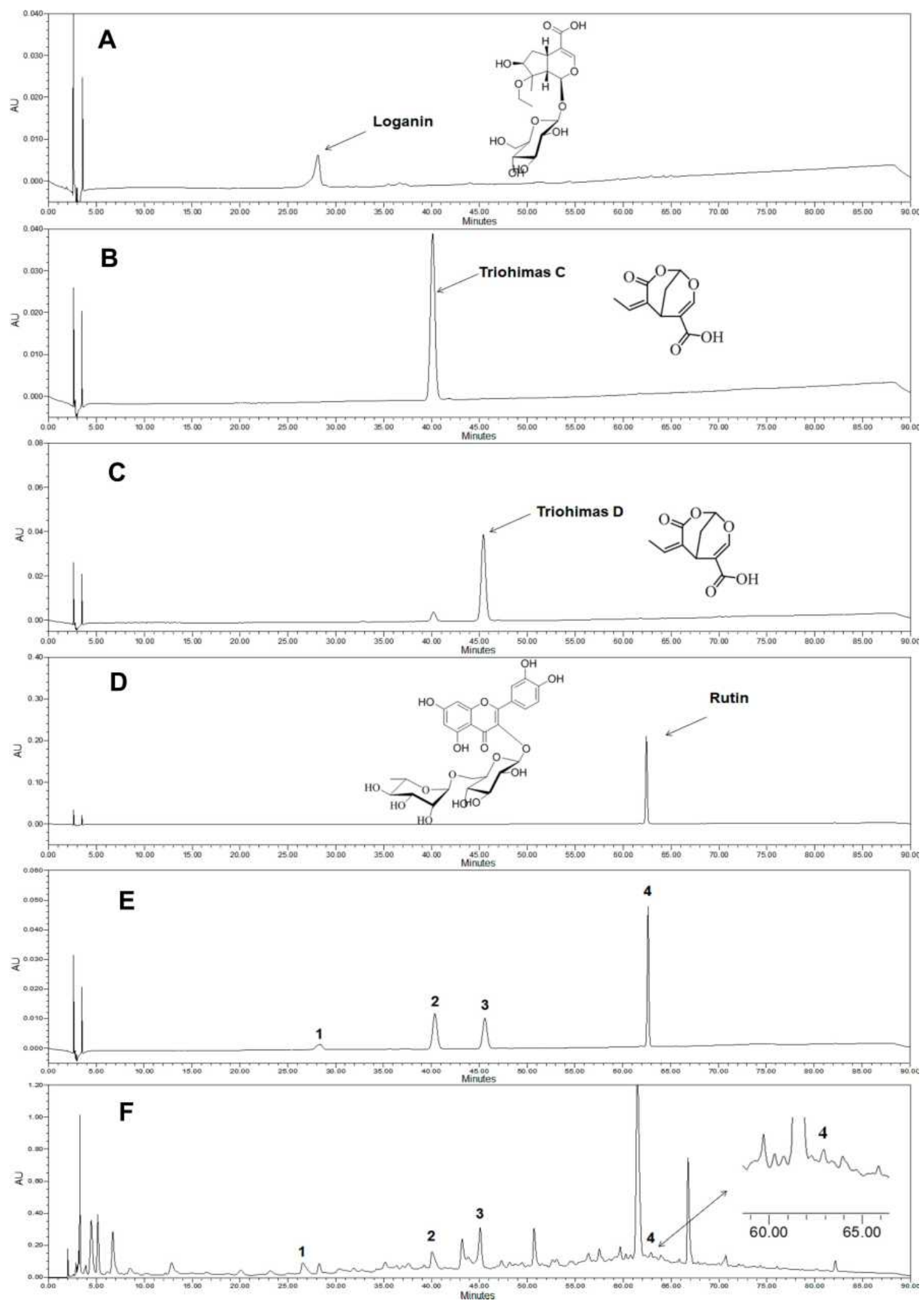

Figure 6 High Performance Liquid Chromatography (HPLC) chromatograms of standard and SZYY. (A-D) The chromatograms of loganin, triohimas C, triohimas D, rutin, respectively. (E) Chromatogram of mixed solution of 4 standard substances. (F) Chromatogram of the typical sample of SZYY. Peak identification: I. Loganin, 2. Triohimas C, 3. Triohimas D, 4. Rutin.

Abbreviation: SZYY, $50 \%$ acetone extract of C.officinalis leaves. 


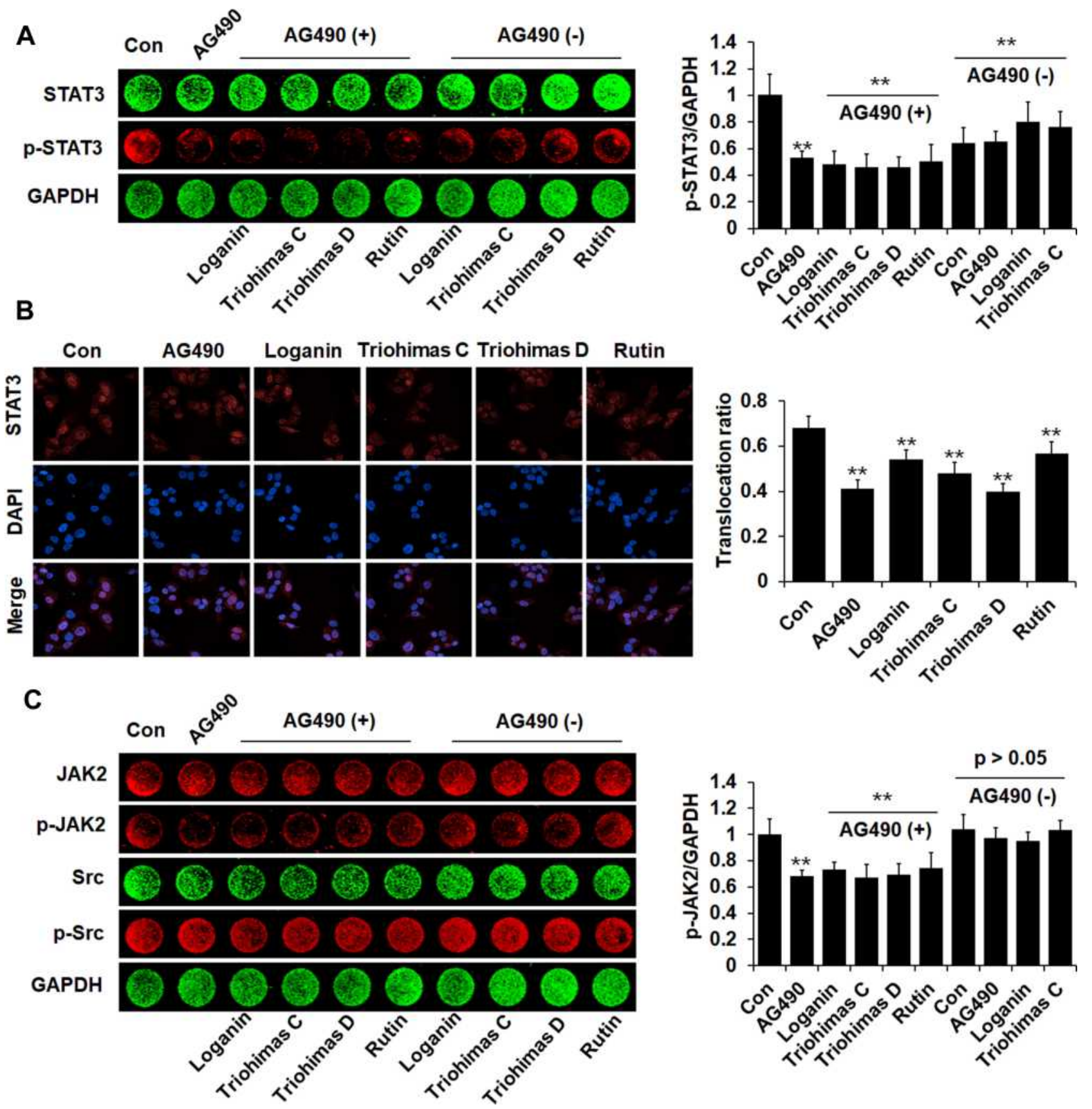

Figure 7 Four compounds restrained phosphorylation/activation and nuclear translocation of STAT3. (A) Phosphorylation of STAT3 in A375 cells was detected by In-cell Western. Histogram illustrated the relative levels of p-STAT3. (B) Representative fluorescent microscopy images of STAT3 nuclear translocation in A375 cells. Scale bar $=50$ $\mu \mathrm{m}$. Histogram illustrated nuclear translocation ratio of STAT3 protein=Mean fluorescence intensity in the nucleus/Cells mean fluorescence intensity. (C) JAK2, P-JAK2, Src and p-Src proteins expression levels in A375 cells were examined by In-cell Western. Histogram illustrated the relative levels of p-JAK2. The fluorescence intensity was normalized to GAPDH. $X \pm S D$. $n=3$ per group. ${ }^{* *} p<0.01$ vs control group.

resulting in tumor survival, therapeutic resistance, and recurrence of cancer. ${ }^{29}$ Here, we observed that SZYY inhibited the expression of the anti-apoptotic proteins Mcl-1, Bcl-xL, and Bcl-2 in tumor tissues and increased the level of caspase-3, an important apoptosis-executing protein (Figure 2C). These proteins are all regulated by STAT3 targeting. ROS are a group of short-lived, highly reactive oxygen-containing molecules that can induce DNA damage and affect the DNA damage response. ${ }^{30}$ The role of ROS in cancer is complicated, and there have been disagreements for a long time. Chiara Gorrini $^{31}$ and Sarah-Maria Fendt ${ }^{32}$ et al considered that oxidative stress plays a dual role in both cancer formation and ROS-based anti-cancer treatment. At low to moderate 

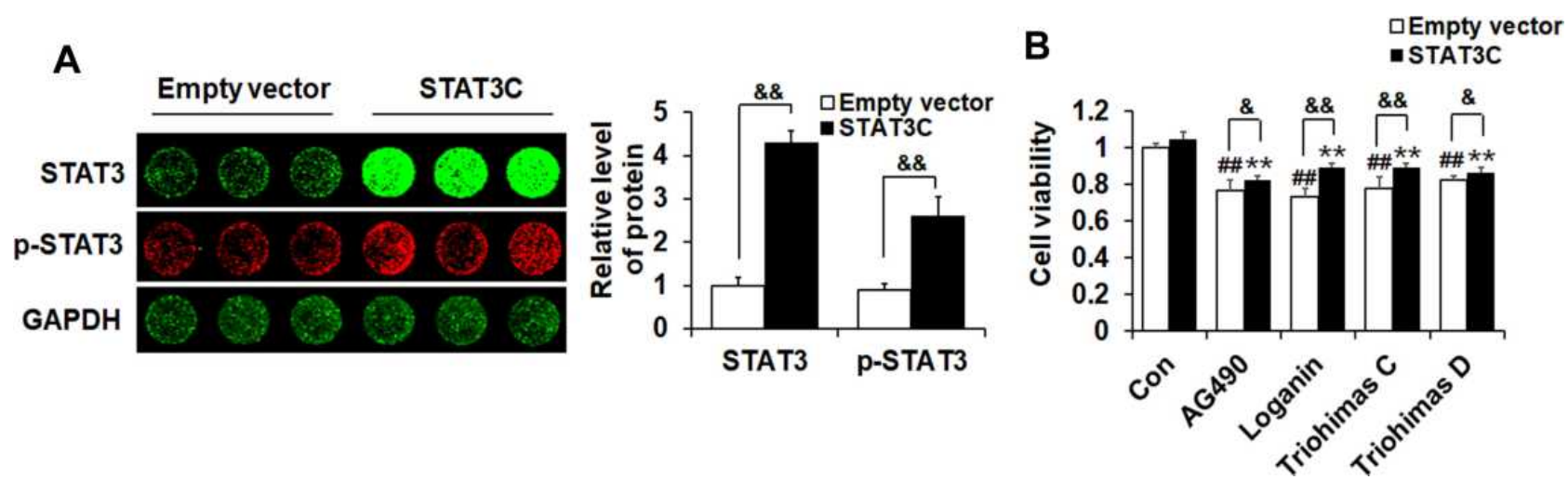

Figure 8 The overexpression of STAT3 weakened the inhibitory effect of SZYY on cells. (A) Protein expression in A375 cells transiently transfected with either Empty vector or h-STAT3 were examined by In-cell Western. Histogram illustrated the relative levels of STAT3 and p-STAT3. The fluorescence intensity was normalized to GAPDH. (B) Effects of STAT3 overexpression on A375 cells proliferation inhibited by SZYY. $X \pm S D$. $n=3$ per group. ${ }^{\# \#} p<0.01$ vs Empty vector control group. ${ }^{* *} p<0.01$ vs STAT3C control group. ${ }^{\&} p<0.05,{ }^{\& \&} p<0.01$ vs cells transfected with the empty vector in each group.

Abbreviation: STAT3C, STAT3-C Flag PRc/CMV.

levels, ROS act as signaling molecules that sustain cellular proliferation and differentiation and activate stress responsive survival pathways. However, excessive ROS production will promote apoptosis and damage cellular components. ${ }^{31}$ Therefore, although cancer cells exhibit consistently higher levels of ROS compared with normal cells, they can still induce targeted cell apoptosis/death by increasing oxidative stress above the toxicity threshold. ${ }^{33}$ In addition, several papers proved that the anti-cancer strategy that triggers ROS generation in cancer cells to induce apoptosis is indeed feasible. ${ }^{31,34-36}$ According to the present study, apoptosis and the production of ROS in tumor tissues were promoted by SZYY (Figure 2A and B), which suggests the increased level of oxidative stress in tumor tissue and the resulting apoptosis/death of tumor cells may also be one of the main mechanisms underlying the anti-melanoma effects of SZYY.

STAT3 is constitutively activated in a majority of melanoma cell lines and tumor specimens. ${ }^{37}$ Studies have shown that STAT3 is involved in the regulation of fundamental biological processes such as cell proliferation, apoptosis, angiogenesis, metastasis, and immune responses. ${ }^{38}$ In this study, we found that SZYY could effectively inhibit the growth and glycolysis of melanoma xenografts in immunodeficient mice (Figure 1A$\mathrm{C}$ and $\mathrm{F}$ ). In addition, cancer therapeutics-related cardiac dysfunction is receiving more attention. Cardiotoxicity related to antitumor drugs, especially cardiac insufficiency, seriously affects the quality of life and prognosis of patients. ${ }^{39}$ Nevertheless, our results revealed that SZYY could effectively improve cardiac function of model mice (Figure 1D). Further research found that
SZYY restrained the phosphorylation/activation of STAT3 in melanoma tissue and lowered the expression of Survivin and Ki-67 (Figures 4A-C and 1E). Survivin is a member of the inhibitor of apoptosis (IAP) gene family, which can inhibit apoptosis and regulate cell mitosis, but overexpression of Survivin in cancer does not simply reflect the presence of a large number of proliferating cells. ${ }^{40-42}$ The cell proliferation antigen Ki-67 is widely used as a cell proliferation marker. Its expression is lower during the G1 and early S phases, and reaches a maximum during the G2 and M phases. ${ }^{43,44} \mathrm{In}$ addition, adequate supply of blood and oxygen and the timely elimination of metabolic waste products play pivotal roles in the growth of solid tumors. Therefore, when the activated tumor cells begin to form tumor masses, the "angiogenesis switch" in them will be turned on. Accumulating evidence suggests that STAT3 activates tumor angiogenesis by directly targeting multiple proangiogenic factors, including VEGF-A, BFGF, and HGF. $^{4}$ VEGF-A, the founding member of the vascular permeability factor (VPF)/VEGF family of proteins, can not only stimulate angiogenesis by activating VEGFR-1 and VEGFR-2, but also induce peritumoral lymph angiogenesis and lymphatic metastasis in animal models. ${ }^{45}$ As with VEGF-A, basic fibroblast growth factor (BFGF) and hepatocyte growth factor (HGF), two other angiogenic factors are also involved in the angiogenesis process during tumorigenesis and development. ${ }^{46}$ Besides, CD31, a specific marker expressed on all cells within the vascular compartment, is able to reflect the density of blood vessels in tumor tissues, which is usually positively correlated with tumor growth and tumor 
metastasis. ${ }^{47,48}$ In this study, we observed that the expression levels of CD31, VEGF-A and BFGF in tumor tissue were reduced by SZYY (Figure 4B and D). Based on this result, we hypothesize that SZYY inhibits tumor angiogenesis via suppressing the expression of CD31, VEGF$\mathrm{A}$ and BFGF.

On the other hand, STAT3 is a vital negative regulator of tumor immune surveillance. Its continuous activation can inhibit the body's anti-tumor immunity, but inhibiting STAT3 in tumor-bearing hosts can enhance the body's innate and adaptive immune responsiveness to tumors. ${ }^{49}$ Our results show that in the SZYY-Low group, the relative abundance of Ly-6G+ neutrophils, F4/80+ macrophages, and CD4+ lymphocytes were significantly altered (Figure $3 \mathrm{~A}$ and $\mathrm{C}$ ). Besides, the processes of interaction between immunocytes from different origins and different cytokines forms the basis of the immune system. ${ }^{50}$ IL-6, IL$17 \mathrm{~A}$, TNF- $\alpha$ and IFN- $\gamma$ are all regulated by STAT $^{4}$ and play crucial roles in coordinating the activities of the innate and adaptive immune systems. ${ }^{51-54}$ We observed by CBA that the levels of IL- 6 , TNF- $\alpha$, IFN- $\gamma$, and IL$17 \mathrm{~A}$ in serum were reduced by SZYY (Figure $3 \mathrm{~B}$ and D). These results revealed that the immune enhancement of SZYY may be achieved through regulating immune cells and the expression of these cytokines in tumor-bearing mice, which may be related to the suppression of STAT3 signaling.

To further explore the pharmacological basis of the anti-melanoma effects of SZYY, the effects of compounds extracted from SZYY on the proliferation of A375 cells were determined. We found that four of them have antitumor pharmacological activities, namely, loganin, triohimas $\mathrm{C}$, triohimas $\mathrm{D}$, and rutin. They all could inhibit the proliferation and migration of A375 cells (Figure 5A-C). At present, some studies have been conducted on the antitumor effects of loganin and rutin. ${ }^{13,55-57}$ However, there is a scarcity of reports of the pharmacological activity of triohimas $\mathrm{C}$ and triohimas D. ${ }^{58,59}$ Further research found loganin, triohimas $\mathrm{C}$, triohimas $\mathrm{D}$, and rutin could inhibit STAT3 phosphorylation/activation and nuclear translocation (Figure 7A and B). Nevertheless, the inhibitory effects of SZYY on A375 cell viability could be partially diminished due to persistent overexpression of STAT3 (Figure 8A and B). Interestingly, JAK2 and Src were less affected by these compounds (Figure 7C), which indicates that these four compounds could exert antimelanoma effects via inhibiting the phosphorylation/activation of STAT3.

\section{Conclusion}

Our results show that SZYY could inhibit the growth of mouse melanoma xenografts, and its effects may be partly achieved by inhibiting STAT3 signaling to induce apoptosis and inhibit tumor angiogenesis. Further experiments have shown that loganin, rutin, triohimas $\mathrm{C}$ and triohimas D may be the active ingredients in SZYY to exert anti-melanoma effects through STAT3 signaling. These findings show the pharmacological effects of SZYY against melanoma at the molecular level and provide an experimental basis for the development of natural anti-melanoma drugs.

\section{Acknowledgments}

This study was supported by the National Key Research and Development Project (2019YFC1708802, 2017YFC1702800), Henan province high-level personnel special support "ZhongYuan One Thousand People Plan" Zhongyuan Leading Talent (ZYQR201810080), the Major Science and Technology Projects in Henan Province: Study on the key technology for quality control and the key characteristics of Rehmannia glutinosa, Dioscorea opposita Thunb and Achyranthes bidentata Blume from Henan Province (171100310500)

\section{Disclosure}

The authors report no conflicts of interest in this work.

\section{References}

1. Merlino G, Herlyn M, Fisher DE, et al. The state of melanoma: challenges and opportunities. Pigment Cell Melanoma Res. 2016;29 (4):404-416. doi:10.1111/pcmr.12475

2. McCarthy M. US melanoma prevalence has doubled over past 30 years. BMJ. 2015;350:h3074. doi:10.1136/bmj.h3074

3. Shah DJ, Dronca RS. Latest advances in chemotherapeutic, targeted, and immune approaches in the treatment of metastatic melanoma. Mayo Clin Proc. 2014;89(4):504-519. doi:10.1016/j.mayocp.2014.02.002

4. Carpenter RL, Lo HW. STAT3 target genes relevant to human cancers. Cancers (Basel). 2014;6(2):897-925. doi:10.3390/cancers6020897

5. Abou-Ghazal M, Yang DS, Qiao W, et al. The incidence, correlation with tumor-infiltrating inflammation, and prognosis of phosphorylated STAT3 expression in human gliomas. Clin Cancer Res. 2008;14 (24):8228-8235. doi:10.1158/1078-0432.CCR-08-1329

6. Lee HT, Xue J, Chou PC, et al. Stat3 orchestrates interaction between endothelial and tumor cells and inhibition of Stat3 suppresses brain metastasis of breast cancer cells. Oncotarget. 2015;6(12): 10016-10029. doi:10.18632/oncotarget.3540

7. Yu H, Pardoll D, Jove R. STATs in cancer inflammation and immunity: a leading role for STAT3. Nat Rev Cancer. 2009;9(11):798-809. doi:10.1038/nrc2734

8. Verdeil G, Lawrence T, Schmitt-Verhulst AM, et al. Targeting STAT3 and STAT5 in tumor-associated immune cells to improve immunotherapy. Cancers (Basel). 2019;11(12). doi:10.3390/ cancers 11121832 
9. Ren YJ, Cao YG, Zeng MN, et al. Two new norsesquiterpenoids with estrogenic activity from the stems and leaves of Dioscorea oppositifolia L. Nat Prod Res. 2019:1-8. doi:10.1080/14786419.2019. 1684284.

10. Yang F, Yue ZG, Wang X, et al. Chemical constituents of leaf of Eucommia ulmoides. Zhongguo Zhong Yao Za Zhi. 2014;39 (8):1445-1449.

11. Liu J. Comparison of efficacy of eucommia ulmoides leaf and bark on hypertension clinical observation of 102 cases. Shaanxi Trad Chin Med. 1980;1:27-30.

12. Zhou C, Hao L, Li K, et al. The inhibitive effect of Eucommia ulmoides leaves extract on abdominal fat. Int J Endocrinol Metab. 2011;31:368-370. doi:10.3760/cma.j.issn.1673-4157.2011.06.003

13. Jin S, Kim KC, Kim JS, et al. Anti-melanoma activities and phytochemical compositions of sorbus commixta fruit extracts. Plants (Basel). 2020;9(9). doi:10.3390/plants9091076

14. Yin $\mathrm{R}, \mathrm{Li} \mathrm{T}$, Tian JX, et al. Ursolic acid, a potential anticancer compound for breast cancer therapy. Crit Rev Food Sci Nutr. 2018;58(4):568-574. doi:10.1080/10408398.2016.1203755

15. Phan AN, Hua TN, Kim MK, et al. Gallic acid inhibition of Src-Stat3 signaling overcomes acquired resistance to EGF receptor tyrosine kinase inhibitors in advanced non-small cell lung cancer. Oncotarget. 2016;7(34):54702-54713. doi:10.18632/oncotarget.10 581

16. Cao HH, Tse AK, Kwan HY, et al. Quercetin exerts anti-melanoma activities and inhibits STAT3 signaling. Biochem Pharmacol. 2014;87(3):424-434. doi:10.1016/j.bcp.2013.11.008

17. Huang J, Zhang Y, Dong L, et al. Ethnopharmacology, phytochemistry, and pharmacology of Cornus officinalis Sieb. et Zucc. $J$ Ethnopharmacol. 2018;213:280-301. doi:10.1016/j.jep.2017.11. 010

18. Pal HC, Hunt KM, Diamond A, et al. Phytochemicals for the Management of Melanoma. Mini Rev Med Chem. 2016;16 (12):953-979. doi:10.2174/1389557516666160211120157

19. Yu X, Li S. Non-metabolic functions of glycolytic enzymes in tumorigenesis. Oncogene. 2017;36(19):2629-2636. doi:10.1038/ onc. 2016.410

20. Kovar JL, Volcheck W, Sevick-Muraca E, et al. Characterization and performance of a near-infrared 2-deoxyglucose optical imaging agent for mouse cancer models. Anal Biochem. 2009;384(2):254-262. doi:10.1016/j.ab.2008.09.050

21. Fontana F, Raimondi M, Di Domizio A, et al. Unraveling the molecular mechanisms and the potential chemopreventive/therapeutic properties of natural compounds in melanoma. Semin Cancer Biol. 2019;59:266-282. doi:10.1016/j.semcancer.2019.06.011

22. Kalal BS, Upadhya D, Pai VR. Chemotherapy resistance mechanisms in advanced skin cancer. Oncol Rev. 2017;11(1):326. doi:10.4081/ oncol.2017.326

23. Ye J, Zhang R, Wu F, et al. Non-apoptotic cell death in malignant tumor cells and natural compounds. Cancer Lett. 2018;420:210-227. doi:10.1016/j.canlet.2018.01.061

24. Sznarkowska A, Kostecka A, Meller K, et al. Inhibition of cancer antioxidant defense by natural compounds. Oncotarget. 2017;8 (9):15996-16016. doi:10.18632/oncotarget.13723

25. Liu N, Wang KS, Qi M, et al. Vitexin compound 1, a novel extraction from a Chinese herb, suppresses melanoma cell growth through DNA damage by increasing ROS levels. J Exp Clin Cancer Res. 2018;37 (1):269. doi:10.1186/s13046-018-0897-x

26. Singh MP, Cho HJ, Kim JT, et al. Morin hydrate reverses cisplatin resistance by impairing PARP1/HMGB1-dependent autophagy in hepatocel lular carcinoma. Cancers (Basel). 2019;11(7). doi:10. 3390/cancers 11070986

27. Ke H, Wang X, Zhou Z, et al. Effect of weimaining on apoptosis and Caspase-3 expression in a breast cancer mouse model. $J$ Ethnopharmacol. 2021;264:113363. doi:10.1016/j.jep.2020.11 3363
28. Wu C, Zhou L, Yuan $\mathrm{H}$, et al. Interconnections among major forms of regulated cell death. Apoptosis. 2020;25(9-10):616-624. doi:10.10 07/s10495-020-01632-2

29. Mohammad RM, Muqbil I, Lowe L, et al. Broad targeting of resistance to apoptosis in cancer. Semin Cancer Biol. 2015;35(Suppl): S78-s103. doi:10.1016/j.semcancer.2015.03.001

30. Srinivas US, Tan BWQ, Vellayappan BA, et al. ROS and the DNA damage response in cancer. Redox Biol. 2019;25:101084. doi:10.1016/j.redox.2018.101084

31. Gorrini C, Harris IS, Mak TW. Modulation of oxidative stress as an anticancer strategy. Nat Rev Drug Discov. 2013;12(12):931-947. doi: $10.1038 /$ nrd4002

32. Fendt SM, Lunt SY. Dynamic ROS Regulation by TIGAR: balancing anti-cancer and pro-metastasis effects. Cancer Cell. 2020;37 (2):141-142. doi:10.1016/j.ccell.2020.01.009

33. Panieri E, Santoro MM. ROS homeostasis and metabolism: a dangerous liason in cancer cells. Cell Death Dis. 2016;7(6): e2253. doi:10.1038/cddis.2016.105

34. Cao Y, Wang J, Tian H, et al. Mitochondrial ROS accumulation inhibiting JAK2/STAT3 pathway is a critical modulator of CYT997-induce d autophagy and apoptosis in gastric cancer. J Exp Clin Cancer Res. 2020;39(1):119. doi:10.1186/s13046-02001621-y

35. Shin J, Song MH, Oh JW, et al. Pro-oxidant actions of carotenoids in triggering apoptosis of cancer cells: a review of emerging evid ence. Antioxidants (Basel). 2020;9(6). doi:10.3390/ antiox 9060532

36. Barrera G. Oxidative stress and lipid peroxidation products in cancer progression and therapy. ISRN Oncol. 2012;2012:137289. doi: $10.5402 / 2012 / 137289$

37. Niu G, Bowman T, Huang M, et al. Roles of activated Src and Stat3 signaling in melanoma tumor cell growth. Oncogene. 2002;21 (46):7001-7010. doi:10.1038/sj.onc.1205859

38. Kortylewski M, Jove R, Yu H. Targeting STAT3 affects melanoma on multiple fronts. Cancer Metastasis Rev. 2005;24(2):315-327. doi:10.1007/s10555-005-1580-1

39. Zhao L. Prevention and treatment of cancer therapeutics-related cardiac dysfunction. Acta Academiae Medicinae Sinicae. 2019;41 (06):842-850. doi:10.3881/j.issn.1000-503X.11380

40. Altieri DC. Survivin and apoptosis control. Adv Cancer Res. 2003;88:31-52. doi:10.1016/s0065-230x(03)88303-3

41. Lens SM, Vader G, Medema RH. The case for Survivin as mitotic regulator. Curr Opin Cell Biol. 2006;18(6):616-622. doi:10.1016/j. ceb.2006.08.016

42. Yamanaka K, Nakahara T, Yamauchi T, et al. Antitumor activity of YM155, a selective small-molecule survivin suppressant, alone and in combinatio $\mathrm{n}$ with docetaxel in human malignant melanoma models. Clin Cancer Res. 2011;17(16):5423-5431. doi:10.1158/ 1078-0432.CCR-10-3410

43. Urruticoechea A, Smith IE, Dowsett M. Proliferation marker Ki-67 in early breast cancer. J Clin Oncol. 2005;23(28):7212-7220. doi:10.1200/JCO.2005.07.501

44. Sobecki M, Mrouj K, Camasses A, et al. The cell proliferation antigen Ki-67 organises heterochromatin. Elife. 2016;5:e13722. doi:10.7554/eLife.13722

45. Björndahl MA, Cao R, Burton JB, et al. Vascular endothelial growth factor-a promotes peritumoral lymphangiogenesis and lymphatic metastasis. Cancer Res. 2005;65(20):9261-9268. doi:10.1158/00085472.CAN-04-2345

46. Ye L, Jiang WG. Bone morphogenetic proteins in tumour associated angiogenesis and implication in cancer therapies. Cancer Lett. 2016;380(2):586-597. doi:10.1016/j.canlet.2015.10.036

47. Woodfin A, Voisin MB, Nourshargh S. PECAM-1: a multi-functional molecule in inflammation and vascular biology. Arterioscler Thromb Vasc Biol. 2007;27(12):2514-2523. doi:10.1161/ATVBAHA.107.15 1456 
48. Zhang YY, Kong LQ, Zhu XD, et al. CD31 regulates metastasis by inducing epithelial-mesenchymal transition in hepatocellular carcinoma via the ITGB1-FAK-Akt signaling pathway. Cancer Lett. 2018;429:29-40. doi:10.1016/j.canlet.2018.05.004

49. Kortylewski M, Kujawski M, Wang T, et al. Inhibiting Stat3 signaling in the hematopoietic system elicits multicomponent antitumor immunity. Nat Med. 2005;11(12):1314-1321. doi:10.1038/nm1325

50. Khaitov RM. Immune system physiology. Ross Fiziol $\mathrm{Zh} \mathrm{Im}$ I M Sechenova. 2000;86(3):252-267.

51. Jones SA, Jenkins BJ. Recent insights into targeting the IL-6 cytokine family in inflammatory diseases and cancer. Nat Rev Immunol. 2018;18(12):773-789. doi:10.1038/s41577-018-0066-7

52. Iwakura Y, Nakae S, Saijo S, et al. The roles of IL-17A in inflammatory immune responses and host defense against pathogens Immunol Rev. 2008;226:57-79. doi:10.1111/j.1600-065X.2008.00 699.x

53. Bertrand F, Rochotte J, Colacios C, et al. Targeting TNF alpha as a novel strategy to enhance CD8+ T cell-dependent immune response in melanoma? Oncoimmunology. 2016;5(1):e1068495. doi:10.1080/ 2162402X.2015.1068495
54. Fenimore J, Young H A. Regulation of IFN-1 Ã Expression. $A d v$ Exp Med Biol. 2016;941:1-19. doi:10.1007/978-94-024-0921-5_1

55. Dang WJ, Chen JH, Zhang N, et al. Study on the inhibitory effect and molecular mechanism of loganin on human malignant melanoma cells. China Medical Herald. 2016;13(12):15-19.

56. Lin JP, Yang JS, Lin JJ, et al. Rutin inhibits human leukemia tumor growth in a murine xenograft model in vivo. Environ Toxicol. 2012;27(8):480-484. doi:10.1002/tox.20662

57. Hu XH, Wang M, Kan JC, et al. Effect and mechanism of Loganin on the proliferation of colon cancer SW480 cells. J Guangdong Pharm Univ. 2015;31(1). doi:10.3969/j.issn.1006-8783.2015.018

58. Chai X, Su Y-F, Zheng Y-H, et al. Iridoids from the roots of Triosteum pinnatifidum. Biochem Syst Ecol. 2010;38:210-212. doi:10.1016/j.bse.2009.12.037

59. Li Z-M, Chen -J-J, Li Y, et al. Two novel iridoids with an unusual $\delta$ lactone-containing skeleton from Triosteum himalayanum. Tetrahedron Lett. 2009;50:4132-4134. doi:10.1016/j.tetlet.2009. 04.111

\section{Publish your work in this journal}

OncoTargets and Therapy is an international, peer-reviewed, open access journal focusing on the pathological basis of all cancers, potential targets for therapy and treatment protocols employed to improve the management of cancer patients. The journal also focuses on the impact of management programs and new therapeutic agents and protocols on patient perspectives such as quality of life, adherence and satisfaction. The manuscript management system is completely online and includes a very quick and fair peer-review system, which is all easy to use. Visit http://www.dovepress.com/ testimonials.php to read real quotes from published authors. 